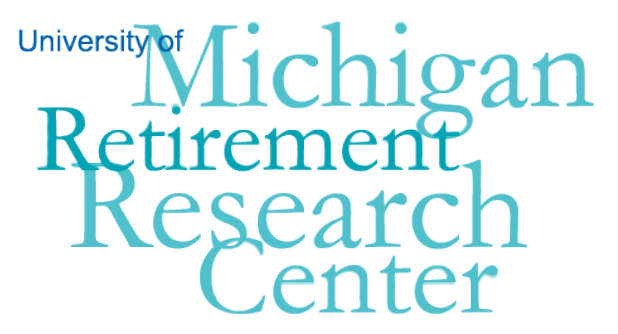

Working Paper WP 2012-275

\title{
Motives for Bequests within the Middle Class
}

\author{
John Laitner and Amanda Sonnega
}

\begin{tabular}{l|l}
\hline $\mathrm{M}$ & $\mathrm{R}$ \\
\hline $\mathrm{R}$ & $\mathrm{C}$ \\
\hline
\end{tabular}

Project \#: UM12-05 



\title{
Motives for Bequests within the Middle Class
}

\author{
John Laitner \\ University of Michigan \\ Amanda Sonnega \\ University of Michigan No \\ November 2012
Michigan Retirement Research Center
University of Michigan
P.O. Box 1248
Ann Arbor, MI 48104
www.mrrc.isr.umich.edu
(734) 615-0422

\section{Acknowledgements}

This work was supported by a grant from the Social Security Administration through the Michigan Retirement Research Center (Grant \# 5 RRC08098401-04-00). The findings and conclusions expressed are solely those of the author and do not represent the views of the Social Security Administration, any agency of the Federal government, or the Michigan Retirement Research Center.

\section{Regents of the University of Michigan}

Julia Donovan Darrow, Ann Arbor; Laurence B. Deitch, Bloomfield Hills; Denise Ilitch, Bingham Farms; Olivia P. Maynard, Goodrich; Andrea Fischer Newman, Ann Arbor; Andrew C. Richner, Grosse Pointe Park; S. Martin Taylor, Gross Pointe Farms; Katherine E. White, Ann Arbor; Mary Sue Coleman, ex officio 


\title{
Motives for Bequests within the Middle Class
}

\begin{abstract}
The life-cycle model of household behavior forms the basis for most economic analysis of Social Security, private pensions, and retirement. This project seeks to extend the usefulness of the lifecycle model by considering the role of middle-class inheritances and bequests. We use HRS data. Prior work by the authors identifies key information in the HRS on the sources of private intergenerational transfers, and it shows that the frequency of couples' inheritances from both spouses' family lines is higher than random behavior would imply. Using additional HRS data on the ratio of parent-to-child lifetime incomes, we analyze the motives behind HRS bequests. We find support for an unintentional transfer model in which bequests arise from residual, unspent parent life-cycle resources. And, we show that our model can account for the frequency of dual inheritances that earlier work revealed.
\end{abstract}




\title{
Motives for Bequests within the Middle Class
}

\author{
John Laitner and Amanda Sonnega
}

\section{November 9, 2012}

This paper studies the prevalence and nature of middle-class bequests in the US. We use data from the HRS. The literature on private intergenerational transfers distinguishes two general types of bequests on the basis of donors' motives: intentional bequests and accidental bequests. Intentional bequests (e.g., Becker [1974], Becker and Tomes [1979], Barro [1974], Laitner [1992], and others) can affect the distribution of wealth (especially its upper tail - e.g., Laitner [2002]), provide insurance within lines of descent (in the sense of redistributing resources from high to low earners), and potentially affect national savings and aggregative private wealth accumulation (see Barro [1974]). Intentional intergenerational transfers may substitute, to some extent, for public assistance in providing resources to both young and old adults. Conversely, households that lack links to relatives may face greater risk than those with extensive networks of family connections. Accidental bequests seem likely to be smaller on average and to occur unpredictably - depending on precautionary saving in an environment with imperfect insurance instruments. Rather than attempting to test for evidence of one or the other category of bequest, this paper sets up a model including both. Then we turn to the HRS. We approach the data with the perspective that both types of bequests may well be present, and we try to assess their relative importance in practice.

The life-cycle model (see Modigliani [1986], Auerbach and Kotlikoff [1987], and others) has provided a basic framework for studying household preparations for retirement, household decisions of when to retire, and household well-being during retirement. Even its strongest adherents admit, however, that inheritances and incentives to bequeath affect many households and may be a significant factor in household planning (e.g., Modigliani [1988], Kotlikoff [1988]). We can understand the life-cycle model better, and perhaps use it more effectively as a tool for analysis, if we can understand the origins and nature of bequests. Moreover, it may be important to establish benchmarks for intergenerational transfers to study subsequent change. The HRS data make such cohort comparisons possible.

The original HRS covers households age 51-61 in 1992, and we study the inheritances of respondent couples. The HRS has an unusually detailed series of questions on private intergenerational transfers - see, for example, Laitner and Sonnega [2010]. As is common in surveys, a "financial respondent" provides answers on behalf of each couple. In the HRS, we can determine which spouse receives each reported inheritance. Laitner and Sonnega show that the data seem distinctly biased — with a financial respondent much more likely to report inheritances from his/her own relatives. In that light, the present paper focuses on the inheritances that financial respondents receive. Nevertheless, we also examine financial respondent transfer receipts conditional on the respondent also reporting transfers to his/her spouse. Distinguishing unconditional from conditional bequest frequencies provides one possible channel for assessing bequest motives. 
Intentional, so-called "altruistic," bequests have received the most attention in the literature. In an altruistic model, a parent cares about his children's utility as well as his/her own, determining his/her bequest plans accordingly. It seems almost assured that such behavior is important for the wealthiest households. Most datasets, including the HRS, cover mainly middle-class households, however. For the middle class, altruistic transfer motives may be inactive. Indeed, papers that have searched for evidence of altruistic transfers have found at most mixed support (e.g., Altonji et al [1992, 1997], Laitner and Juster [1996], Laitner and Ohlsson [2001], and others).

"Accidental bequests," which arise when a household dies with unannuitized assets remaining but no specific intent to leave an estate, have also received attention (e.g., Kotlikoff and Spivak [1981], Davies [1981], Hurd [1989], Friedman and Warshawsky [1990], and others). A new literature (e.g., Laitner and Stolyarov [2012], DeNardi et al [2010], and Sinclair and Smetters [2004]) expands the model to include health concerns in old age. In the simplest case, accidental bequests arise randomly in the population of parent households. Purely random transfers could not explain the high conditional probability of an inheritance in the HRS described above. On the other hand, a mixture of intentional and accidental bequests could, and we look for evidence of that eventuality. The more sophisticated models of unintentional bequest behavior in the more recent literature are another possibility that we consider.

Turning to results, we first examine the degree to which mating is assortative in terms of spouses tending to come from similar economic backgrounds. We provide evidence from the HRS. The degree to which mating is assortative on backgrounds has a bearing on the remainder of our analysis.

Second, we present a model of household behavior that incorporates both intentional and accidental bequests, we derive a simple probit-equation formulation describing inheritance receipt, and we estimate the probit's parameters from HRS data. As stated, we focus on data on the inheritances of financial respondents. We argue that a hallmark of intentional bequests is dependence on the relative lifetime resource ratio of donors versus benefactors, and we use the HRS to derive a 5-part summary of parent-to-child relative resources.

We find some support for intentional bequest theories: a higher ratio of parent-to-child lifetime resources seems positively associated with a higher (parental) bequest. But, the evidence seems limited.

We do find fairly strong evidence of a reduction in bequest activity at the very lowest parent-to-child resource ratios — and we suggest that accidental bequest behavior may provide the explanation.

Third, the HRS enables us to distinguish which financial respondents report that their spouses have received inheritances. The frequency of own inheritance is double, conditional on reporting an inheritance for one's spouse (see Laitner and Sonnega [2010]). This might seem to point to a combination of strongly assortative mating and intentional bequest behavior. We argue, however, that an accidental bequest model that is more sophisticated than the simplest variants may provide a better explanation.

The organization of this paper is as follows. Section 2 examines evidence within the HRS of assortative mating on economic background. Section 3 presents our theoretical 
model, which has both intentional and accidental intergenerational transfers. We argue that this framework is needed since the two types of bequests will likely be intermixed in practice. Section 4 presents our empirical analysis. Section 5 concludes.

2 Assortative Mating. It seems possible that if one spouse has inherited, the other is likely to have had an inheritance as well. A possible reason is a combination of assortative mating and intentional-bequest behavior: if parents and parents in-law tend to have similar circumstances, we would not be surprised to observe child households either receiving no inheritance at all or inheritances from both sets of parents. There is a great deal of evidence that people tend to choose marital partners with attributes and backgrounds similar to their own (e.g., Laitner [1991]). ${ }^{1}$ For example, spousal educational attainments tend to be very strongly correlated. This section examines assortative mating with respect to a particular aspect of economic background that Section 3 shows should be highly related to intentional bequest behavior.

In 1994, the HRS asked both members of each couple about their parents' standard of living relative to their own. The questions were as follows.

W5851 When your parents were your age, were their living standards (1) higher, (2) lower, or (3) the same as yours are now?

W5852 Would you say much higher, (1) Yes, (5) No?

W5853 Would you say much lower, (1) Yes, (5) No?

In all, we have data for 3,582 couples in which both spouses answered W5851 (with responses in the set $\{1,2,3\})$. Table 1 presents results. The columns correspond to the original-sample member of the couple and the rows to the original-sample member's spouse.

The row and column sums in Table 1 are nearly identical. If we average the two lists of probabilities to column vector $v$, the matrix $v v^{\prime}$ provides the expected population fractions under purely random mating. See Table 2. Though Tables 1-2 appear surprisingly similar, that is partly due to the very large fraction of individuals reporting that their parents had a lower standard of living than their own. A chi-squared test that Tables 1-2 are identical, in fact, rejects, yielding a statistic 89.78 - the $1 \%$ critical value, with 8 degrees of freedom, being 20.1 .

There is some evidence of assortative mating: the (higher, higher) entry for Table 1, for instance, is 2-3 times the same for Table 2. On the other hand, with purely assortative mating, the outcome would be Table 3 - with principal diagonal $v$, and zeros elsewhere. Yet, Table 3 is clearly not a good description of our data.

We attempt to assess the degree of assortativity in more detail as follows. We want to use all 3 survey questions: W5851-53. We construct a 5-part scale: (1) corresponds to response "lower" for W5851 and "much lower" for W5853; (2) corresponds to "lower" for W5851 and "no" for W5853; (3) corresponds to "same" for W5851; (4) corresponds

\footnotetext{
1 See also Becker [1980].
} 
Table 1. Marital Fractions based upon Standard of Living of Parents Relative to Respondent

\begin{tabular}{|c|c|c|c|c|}
\hline \multirow{2}{*}{$\begin{array}{c}\text { Std. of Living } \\
\text { Parents Relative } \\
\text { to Self }\end{array}$} & \multicolumn{2}{|c|}{ Std. of Living Parents Relative to Self } & $\begin{array}{c}\text { Row } \\
\text { Sum }\end{array}$ \\
\cline { 2 - 4 } & Lower & Same & Higher & \\
\hline Lower & 0.4980 & 0.1354 & 0.0466 & 0.6801 \\
\hline Same & 0.1505 & 0.0625 & 0.0212 & 0.2342 \\
\hline Higher & 0.0480 & 0.0204 & 0.0173 & 0.0857 \\
\hline Column Sum & 0.6965 & 0.2183 & 0.0851 & 1.0000 \\
\hline
\end{tabular}

Table 2. Marital Fractions with Purely Random Mating

\begin{tabular}{|c|c|c|c|c|}
\hline \multirow{2}{*}{$\begin{array}{c}\text { Std. of Living } \\
\text { Parents Relative } \\
\text { to Self }\end{array}$} & \multicolumn{2}{|c|}{ Std. of Living Parents Relative to Self } & $\begin{array}{c}\text { Row } \\
\text { Sum }\end{array}$ \\
\cline { 2 - 4 } & Lower & Same & Higher & \\
\hline Lower & 0.4738 & 0.1557 & 0.0588 & 0.6883 \\
\hline Same & 0.1557 & 0.0512 & 0.0193 & 0.2263 \\
\hline Higher & 0.0588 & 0.0193 & 0.0073 & 0.0854 \\
\hline Column Sum & 0.6883 & 0.2263 & 0.0854 & 1.0000 \\
\hline
\end{tabular}

Table 3. Marital Fractions with Purely Assortative Mating

\begin{tabular}{|c|c|c|c|c|}
\hline \multirow{2}{*}{$\begin{array}{c}\text { Std. of Living } \\
\text { Parents Relative } \\
\text { to Self }\end{array}$} & \multicolumn{2}{|c|}{ Std. of Living Parents Relative to Self } & Row \\
\cline { 2 - 4 } & Lower & Same & Higher & \\
\hline Lower & 0.6883 & 0.0000 & 0.0000 & 0.6883 \\
\hline Same & 0.0000 & 0.2263 & 0.0000 & 0.2263 \\
\hline Higher & 0.0000 & 0.0000 & 0.0854 & 0.0854 \\
\hline Column Sum & 0.6883 & 0.2263 & 0.0854 & 1.0000 \\
\hline
\end{tabular}


to "higher" for W5851 and "no" to W5852; and, (5) corresponds to "higher" for W5851 combined with "much higher" for W5852.

Let $f(x, y, \rho)$ be the bivariate normal density for $(x, y)$ if the individual means are 0 , the standard deviations 1 , and the correlation $\rho \in[-1,1]$. Let $y \in\{1, \ldots, 5\}$ be the sample member's answer to W5851-53; and, let $x \in\{1, \ldots, 5\}$ be the same for the spouse. We want to estimate $\left(\lambda_{1}, \ldots, \lambda_{4}, \rho\right)$ such that

$$
\begin{gathered}
\operatorname{Prob}\{(x, y)=(i, j)\}=\int_{\lambda_{i-1}}^{\lambda_{i}} \int_{\lambda_{j-1}}^{\lambda_{j}} f(x, y, \rho) d y d x \\
\lambda_{0}=-\infty \quad \text { and } \quad \lambda_{5}=\infty
\end{gathered}
$$

We use a bivariate probit model.

The probit analysis has several advantages over comparisons of tables. On the one hand, it allows us to use observations in which a respondent provides an answer to W5851 but not W5852 or W5853. In such cases, we can expand the range of integration for, say, $y$, to $\lambda_{j+1}$ to $\lambda_{j-1}$. On the other hand, it allows us to treat couples with, say, $(x, y)=(3,4)$ as "close" to the assortative outcome despite $x \neq y$.

Table 4 presents maximum likelihood estimates. The estimate of $\rho$ is ${ }^{2}$

$$
\widehat{\rho}=0.1957, \quad \text { S.E. }=0.0201 \text {. }
$$

With random mating, $\rho=0.00$; perfectly assortative mating implies $\rho=1.00$. Our estimate is in-between. If we assume that mating is very highly assortative, evidently parental standard of living is only one of many characteristics governing choice of marital partner.

Our analysis below makes use of questions W5851-53, and we use Table 4 to aid in our interpretations.

3 Joint Model of Altruistic and Accidental Bequests. Our plan is to develop a composite model that emphasizes the two main theories of private intergenerational transfers, i.e., the Barro-Becker altruistic model of intentional bequests and the KotlikoffHurd-Friedman-Warshawsky model of accidental bequests.

Digressing for a moment, intentional bequests can be either "altruistic," in which the donor cares about both his/her own lifetime utility and the utility of his/her descendants, using a comparison of the two to determine the bequest amount, or what we might call "egoistic," in which case the donor derives pleasure from making a transfer regardless of its effect on his/her descendants' utility. Empirical analysis of altruistic transfers requires information on economic resources for several generations in each family line; analysis of egoistic transfers, in contrast, only requires information on the donor's wherewithal. The accidental-bequest model is inherently egoistic in nature. In this paper, we actually want to contrast the altruistic and egoistic theories - grouping egoistic intentional bequests with

2 If we allow 9 parameters - say, $\lambda_{1}, \ldots, \lambda_{4}$ for $i ; \bar{\lambda}_{1}, \ldots, \bar{\lambda}_{4}$ for $j$; and, $\rho$ - we find $\widehat{\rho}=0.2161$, standard error $=0.0208$. 


\begin{tabular}{|c|c|c|}
\hline \multicolumn{3}{|c|}{$\begin{array}{c}\text { Table 4. Maximum Likelihood Estimation of Bivariate Probit } \\
\text { Parameter (Standard Error) }\end{array}$} \\
\hline $\begin{array}{l}\text { Variable } \\
\text { Name }\end{array}$ & $\begin{array}{l}\text { Parameter } \\
\text { Estimate }\end{array}$ & $\begin{array}{l}\text { Standard } \\
\text { Error }\end{array}$ \\
\hline$\lambda_{1}$ & $-0.0627^{* * *}$ & 0.0157 \\
\hline$\lambda_{2}$ & $0.4906^{* * *}$ & 0.0164 \\
\hline$\lambda_{3}$ & $1.3688^{* * *}$ & 0.0219 \\
\hline$\lambda_{4}$ & $1.6574^{* * *}$ & 0.0259 \\
\hline$\rho$ & $0.1957^{* * *}$ & 0.0201 \\
\hline -Log Likelihood & \multicolumn{2}{|c|}{$0.917285 \mathrm{E}+04$} \\
\hline Number Households & \multicolumn{2}{|c|}{3582} \\
\hline
\end{tabular}

Variables with ${ }^{*}, * *$, and $* * *$ are significant at the 10,5 , and $1 \%$ level, respectively.

accidental bequests. ${ }^{3}$ Accordingly, we henceforth use the terms "intentional bequests" and "altruistic bequests" synonymously.

Consider a single-person household with a maximal life span of two periods. The household has an adult child, whose life span overlaps the parent for one period. For simplicity, set the interest rate to zero. The parent household's probability of surviving one period is 1 ; the probability of second-period-of-life survival is $p \in(0,1)$. The parent household weights its second-period utility with $A>0$, and its own benefit from its adult child's utility with $A \cdot B>0$. Let $a>0$ be the parent household's lifetime earnings, all of which arrive in its first period of life, plus its inheritance (if any), which also arrives in the first period of life (i.e., "a" stands for the parents' "assets.") Let $s$ be the parents' savings carried from period 1 to 2 of life, let $y$ be the adult child's earnings, and let $b \geq 0$ be the parent household's intentional bequest. Assuming a logarithmic flow-of-utility function, the parent household's expected lifetime utility, as viewed from its first-period of life, is

$$
\ln (a-s)+A \cdot\{p \cdot[\ln (s-b)+B \cdot \ln (b+y)]+B \cdot(1-p) \cdot \ln (s+y)\} .
$$

For any $s$, the parent household chooses $b \geq 0$ to maximize

$$
\ln (s-b)+B \cdot \ln (b+y)
$$

First-order conditions yield

$$
b=\max \left\{0, \frac{B \cdot s-y}{1+B}\right\}
$$

For simplicity, we treat all variables as nonstochastic.

3 The Becker, Tomes, Barro, and Laitner models referenced above model intentional, altruistic transfers. Examples of intentional, egoistic transfers include, for instance, Blin$\operatorname{der}[1974]$. 
Second-period-of-life utility for the parent household is

$$
\begin{aligned}
v(s, y) & \equiv p \cdot\left[\ln \left(s-\max \left\{0, \frac{B \cdot s-y}{1+B}\right\}\right)+B \cdot \ln \left(\max \left\{0, \frac{B \cdot s-y}{1+B}\right\}+y\right)\right] \\
& +(1-p) \cdot B \cdot \ln (s+y) .
\end{aligned}
$$

We can see that $v(.,$.$) is increasing in s$ and concave. ${ }^{4}$

The parent household's first-period-of-life problem is

$$
\max _{s}\{\ln (a-s)+A \cdot v(s, y)\}
$$

Let the optimal $s$ be

$$
s^{*}=s^{*}(a, y) \text {. }
$$

We can see that $s^{*}(.,$.$) is homogeneous of degree 1$, increasing in $a$, and decreasing in $y$.

The parent household's expected actual amount bequeathed is

$$
b^{*}=b^{*}(a, y)=p \cdot \max \left\{0, \frac{B \cdot s^{*}(a, y)-y}{1+B}\right\}+(1-p) \cdot s^{*}(a, y) .
$$

We can see that $b^{*}(.,$.$) is homogeneous of degree 1$, increasing in $a$, and decreasing in $y$. Using the homogeneity of degree 1 , divide (8) through by $a$ :

$$
b^{*} / a=b^{*}(1, y / a)=p \cdot \max \left\{0, \frac{B \cdot s^{*}(1, y / a)-y / a}{1+B}\right\}+(1-p) \cdot s^{*}(1, y / a) .
$$

If $B=0$, we have an accidental-bequest model. In that case, $s^{*}(.,$.$) , and hence$ $b^{*}(.,$.$) , depends upon a$ but not $y$. Hence, when $B=0, b^{*} / a$ is a constant. If $B>0$, we have an intentional-bequest model. Even in the latter case, however, (8)-(9) show that actual bequests are a mixture of accidental and intentional transfers.

Despite its simplicity, the simple model illustrates 3 important points. First, it shows that the parent household's altruistic bequest depends, negatively, upon $y / a$. The higher the parent resources relative to the child's, the larger the altruistic bequest the parent will want to make. This dependence on intergenerational resource comparisons is a hallmark of the altruistic model. Second, we see the potential importance of the non-negativity constraint $b \geq 0$. Even if $A \cdot B>0$ - so that the parent household cares about its adult child - a high $y / a$ may still lead the parents to want to extract resources from the child rather than to make a positive bequest. The non-negativity constraint will bind in the latter case. When we observe a zero bequest in the population, that does not necessarily indicate an absence of altruism. Third, the model shows that accidental bequests occur stochastically - when life is short. A positive accidental bequest does not indicate whether the donor household would have made an altruistic bequest had it lived longer.

4 To see the last, note that $v($.$) comes from maximizing a concave function with respect$ to $b$, with the latter restricted to a convex set. 
4 Empirical Analysis. We estimate a linearized version of (9).

As stated, questions W5851-3 potentially provide five discrete measures of $y / a$. Drop those with the highest ratios (i.e., those with W5851=2 and W5853=1), and let the remaining four categories determine, for the financial respondent of child household $i$ (i.e., respondent household $i$ in our HRS sample), a system of dummy variables $\left\{x_{i 2}, x_{i 3}, x_{i 4}, x_{i 5}\right\}$ as follows:

$$
\begin{gathered}
x_{i 2}= \begin{cases}1, & \text { if W } 5851=2 \text { and W } 5853=5, \\
0, & \text { otherwise, }\end{cases} \\
x_{i 3}= \begin{cases}1, & \text { if W } 5851=3, \\
0, & \text { otherwise, }\end{cases} \\
x_{i 4}= \begin{cases}1, & \text { if W5851=1 and W } 5852=5, \\
0, & \text { otherwise, }\end{cases} \\
x_{i 5}= \begin{cases}1, & \text { if W5851=1 and W } 5852=1 \\
0, & \text { otherwise. }\end{cases}
\end{gathered}
$$

If, for example, the financial respondent of child household $i$ reports that his/her parents' standard of living was much higher than his/her own, we have $x_{i 2}=0=x_{i 3}=x_{i 4}$ and $x_{i 5}=1$. Let

$$
x_{i 1} \equiv 1 .
$$

Let $\epsilon \sim \mathcal{N}\left(0, \sigma^{2}\right)$.

A linearized version of $(9)$ is

$$
b_{i}^{*} / a_{i}=\sum_{j=1}^{5} \alpha_{j} \cdot x_{i j}+\epsilon_{i} .
$$

Intentional bequest behavior in (9) implies

$$
0 \leq \alpha_{2} \leq \alpha_{3} \leq \alpha_{4} \leq \alpha_{5} ;
$$

accidental bequests (i.e., egoistic behavior) alone would lead to

$$
0=\alpha_{2}=\alpha_{3}=\alpha_{4}=\alpha_{5} .
$$

In the intentional-bequest case, (9) might imply that only parents whose lifetime resources are above their children's are likely to surmount the non-negativity constraint on $b$; hence, we might, for example, find

$$
0=\alpha_{2}=\alpha_{3}<\alpha_{4}<\alpha_{5} .
$$

Accidental bequests will affect the magnitude of $\alpha_{1}$ but not, in our simple model, $\alpha_{j}, j>1$. Rescale to 


$$
\beta_{j} \equiv \alpha_{j} / \sigma
$$

Then

$$
\epsilon_{i} \sim \mathcal{N}(0,1)
$$

A positive bequest requires

$$
\sum_{j=1}^{5} \beta_{j} \cdot x_{i j}+\epsilon_{i}>0
$$

We have

$$
\operatorname{Prob}\left\{\sum_{j=1}^{5} \beta_{j} \cdot x_{i j}+\epsilon_{i}>0\right\}=1-\Phi\left(-\sum_{j=1}^{5} \beta_{j} \cdot x_{i j}\right)=\Phi\left(\sum_{j=1}^{5} \beta_{j} \cdot x_{i j}\right),
$$

where $\Phi($.$) is the cumulative distribution function for the standardized normal. The ab-$ sence of a bequest for household $i$ implies the opposite sign in (16), for which the probability is

$$
\operatorname{Prob}\left\{\sum_{j=1}^{5} \beta_{j} \cdot x_{i j}+\epsilon_{i} \leq 0\right\}=\Phi\left(-\sum_{j=1}^{5} \beta_{j} \cdot x_{i j}\right) .
$$

We use maximum likelihood estimation. Let

$$
\chi_{i} \equiv \begin{cases}1, & \text { if } b^{*}\left(1, y_{i} / a_{i}\right)>0 \\ 0, & \text { otherwise }\end{cases}
$$

We solve

$$
\max _{\beta_{1}, \ldots, \beta_{5}}\left\{\sum_{\left\{i \mid \chi_{i}=1\right\}} \ln \left(\Phi\left(\sum_{j=1}^{5} \beta_{j} \cdot x_{i j}\right)\right)+\sum_{\left\{i \mid \chi_{i}=0\right\}} \ln \left(\Phi\left(-\sum_{j=1}^{5} \beta_{j} \cdot x_{i j}\right)\right)\right\} .
$$

Tables 5-6. Tables 5-6 present results. In Table 5, we use the 5-part dichotomy from W5851-53; in Table 6, we use a 3-part split from W5851 alone. In all cases, we use 1992 married couples all of whose parents are deceased. Tables 5A and 6A use unweighted data; Tables 5B and 6B employ HRS household weights.

The first column of Table 5A uses a single regressor, a constant. Laitner and Sonnega [2010] show that the frequency of inheritances (for financial respondents) is 0.20-0.25; hence, we expect the coefficient of the constant in our probit to be negative. In words, in the probit, we have a normal random variable with standard deviation 1 . Realizations that are negative are associated with zero inheritances. The $\beta_{1}<0$ in column 1 shifts the mean of the normal distribution to the left. We need it to be far enough to the left that 
the probability of a positive realization is only $0.20-0.25$. The sign and the magnitude of our estimated $\beta_{1}$, therefore, make sense.

Turning to Table 5A, column 5, we can see that the monotonicity that we expected recall (11) - fails. With the weighted sample of Table 5B, on the other hand, monotonicity almost holds, and all but one of the coefficients is significantly different from 0 at the 5 percent level. ${ }^{5}$ On balance, the intentional bequest model receives some support, especially in Table 5B, column 5.

The text suggests that we would not be surprised to see $\beta_{2}=0=\beta_{3}$ - recall (13). The latter definitely does not arise. In fact, with the unweighted sample,

$$
\beta_{2} \approx \beta_{3} \approx \beta_{4} \approx \beta_{5}
$$

The same is roughly the case in Table 5B as well. The lowest parent relative income category is omitted; hence, we might conclude that bequest behavior disappears for parents who are quite poor relative to their children, but is fairly even for the remainder of the population. Columns 2-4 of Tables 5A-B do nothing to dispel this impression.

On the whole, (21) does not seem consistent with the spirit of the altruistic model. Furthermore, even to have children with a 50:50 chance of receiving an inheritance, we need $\sum \beta_{j} \cdot x_{i j}=0$, and the latter never comes close in Tables $5 \mathrm{~A}-\mathrm{B}$ - even with $x_{i 5}>0$.

Results in Tables 6A-B are similar, though monotonicity seems even more tenuous.

An accidental bequest model more sophisticated than (9) could be consistent with the probit outcomes. Laitner and Stolyarov [2012], DeNardi et al [2010], and Sinclair and Smetters [2004] suggest models in which although parents are life-cycle savers, they prepare not only for routine consumption in retirement but also for health emergencies. Households with low income may make modest preparations in the latter regard, planning to rely upon Social Security, SSI, Medicare, and Medicaid. These households, consequently, will tend to have low and infrequent accidental bequests. Remaining households will have accidental bequests if their medical expenses are low and their longevity short. Such models could offer an explanation of (21).

5 Recall from Section 2 above that the number of observations with $x_{i 2} \neq 0$ and $x_{i 3} \neq 0$ are 5-10 times larger than those for $x_{i 4}$ and $x_{i 5}$ - tending to give $\beta_{2}$ and $\beta_{3}$ smaller standard errors. 
Table 5A. Maximum Likelihood Estimation of 5-Parameter Probit: Parameter/(Standard Error)

[HRS 1992, Married Households with All Parents Deceased, Unweighted]

\begin{tabular}{|c|c|c|c|c|c|}
\hline Variable & Reg 1 & Reg 2 & Reg 3 & Reg 4 & Reg 5 \\
\hline $\begin{array}{c}\beta_{1} \\
\text { (S.E.) }\end{array}$ & $\begin{array}{c}-0.7436^{* * *} \\
(0.0417)\end{array}$ & $\begin{array}{c}-0.7521^{* * *} \\
(0.0427)\end{array}$ & $\begin{array}{c}-0.7567^{* * *} \\
(0.0435)\end{array}$ & $\begin{array}{c}-0.8336^{* * * *} \\
(0.0505)\end{array}$ & $\begin{array}{c}-0.9281^{* * * *} \\
(0.0600)\end{array}$ \\
\hline $\begin{array}{c}\beta_{2} \\
\text { (S.E.) }\end{array}$ & .. & $\begin{array}{c}0.1955 \\
(0.2023)\end{array}$ & $\begin{array}{c}0.1231 \\
(0.2232)\end{array}$ & $\begin{array}{c}0.3167^{* * *} \\
(0.1007)\end{array}$ & $\begin{array}{c}0.3471^{* * *} \\
(0.1126)\end{array}$ \\
\hline $\begin{array}{c}\beta_{3} \\
\text { (S.E.) }\end{array}$ & .. & .. & $\begin{array}{c}0.2001 \\
(0.2025)\end{array}$ & $\begin{array}{c}0.1999 \\
(0.2246)\end{array}$ & $\begin{array}{c}0.4113^{* * *} \\
(0.1058)\end{array}$ \\
\hline $\begin{array}{c}\beta_{4} \\
\text { (S.E.) }\end{array}$ & .. & .. & .. & $\begin{array}{c}0.2769 \\
(0.2041)\end{array}$ & $\begin{array}{c}0.2945 \\
(0.2270)\end{array}$ \\
\hline $\begin{array}{c}\beta_{5} \\
\text { (S.E.) }\end{array}$ & .. & .. & .. & .. & $\begin{array}{l}0.3715^{*} \\
(0.2067)\end{array}$ \\
\hline D.F. & 1106 & 1105 & 1104 & 1103 & 1102 \\
\hline -Log Likelihood & $0.595027 \mathrm{E}+03$ & $0.594568 \mathrm{E}+03$ & $0.594417 \mathrm{E}+03$ & $0.589537 \mathrm{E}+03$ & $0.584847 \mathrm{E}+03$ \\
\hline
\end{tabular}

Variables with $*, * *$, and ${ }^{* * *}$ are significant at the 10,5 , and $1 \%$ level, respectively.

Table 5B. Maximum Likelihood Estimation of 5-Parameter Probit: Parameter/(Standard Error)

[HRS 1992, Married Households with All Parents Deceased, Weighted]

\begin{tabular}{|c|c|c|c|c|c|}
\hline Variable & Reg 1 & Reg 2 & Reg 3 & Reg 4 & Reg 5 \\
\hline $\begin{array}{c}\beta_{1} \\
\text { (S.E.) }\end{array}$ & $\begin{array}{c}-0.6768^{* * *} \\
(0.0410)\end{array}$ & $\begin{array}{c}-0.6876^{* * *} \\
(0.0418)\end{array}$ & $\begin{array}{c}-0.6940^{* * *} \\
(0.0426)\end{array}$ & $\begin{array}{c}-0.7632^{* * *} \\
(0.0496)\end{array}$ & $\begin{array}{c}-0.8451^{* * *} \\
(0.0591)\end{array}$ \\
\hline $\begin{array}{c}\beta_{2} \\
\text { (S.E.) }\end{array}$ &.. & $\begin{array}{c}0.2873 \\
(0.2119)\end{array}$ & $\begin{array}{c}0.1920 \\
(0.2302)\end{array}$ & $\begin{array}{c}0.2755^{* * *} \\
(0.0976)\end{array}$ & $\begin{array}{c}0.2914^{* * *} \\
(0.1097)\end{array}$ \\
\hline $\begin{array}{c}\beta_{3} \\
\text { (S.E.) }\end{array}$ & .. & .. & $\begin{array}{c}0.2937 \\
(0.2121)\end{array}$ & $\begin{array}{c}0.2612 \\
(0.2316)\end{array}$ & $\begin{array}{c}0.3574^{* * *} \\
(0.1027)\end{array}$ \\
\hline $\begin{array}{c}\beta_{4} \\
\text { (S.E.) }\end{array}$ & .. & .. & 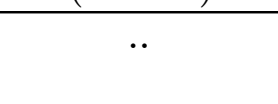 & $\begin{array}{l}0.3629^{*} \\
(0.2136)\end{array}$ & $\begin{array}{c}0.3430 \\
(0.2338)\end{array}$ \\
\hline $\begin{array}{c}\beta_{5} \\
\text { (S.E.) }\end{array}$ & .. & .. & .. &.. & $\begin{array}{l}0.4447^{* *} \\
(0.2160)\end{array}$ \\
\hline D.F. & 1106 & 1105 & 1104 & 1103 & 1102 \\
\hline -Log Likelihood & $0.621627 \mathrm{E}+03$ & $0.620725 \mathrm{E}+03$ & $0.620382 \mathrm{E}+03$ & $0.616433 \mathrm{E}+03$ & $0.612939 \mathrm{E}+03$ \\
\hline
\end{tabular}

Variables with ${ }^{*},{ }^{* *}$, and ${ }^{* * *}$ are significant at the 10,5 , and $1 \%$ level, respectively. 
Table 6A. Maximum Likelihood Estimation of 3-Parameter Probit: Parameter/(Standard Error)

[HRS 1992, Married Households with All Parents Deceased, Unweighted]

\begin{tabular}{|c|c|c|c|}
\hline Variable & Reg 1 & Reg 2 & Reg 3 \\
\hline$\beta_{1}$ & $-0.7436^{* * *}$ & $-0.7567^{* * *}$ & $-0.8336^{* * *}$ \\
(S.E.) & $(0.0417)$ & $(0.0435)$ & $(0.0505)$ \\
\hline$\beta_{2}$ &.$\cdot$ & 0.1653 & $0.3167^{* * *}$ \\
(S.E.) & & $(0.1530)$ & $(0.1007)$ \\
\hline$\beta_{3}$ &.. &. & 0.2421 \\
(S.E.) & & 1105 & 1104 \\
\hline D.F. & 1106 & $0.1551)$ \\
\hline -Log Likelihood & $0.595027 \mathrm{E}+03$ & $0.594451 \mathrm{E}+03$ & $0.589571 \mathrm{E}+03$ \\
\hline
\end{tabular}

Variables with ${ }^{*}, * *$, and ${ }^{* * *}$ are significant at the 10, 5, and $1 \%$ level, respectively.

Table 6B. Maximum Likelihood Estimation of 3-Parameter Probit: Parameter/(Standard Error)

[HRS 1992, Married Households with All Parents Deceased, Weighted]

\begin{tabular}{|c|c|c|c|}
\hline Variable & Reg 1 & Reg 2 & Reg 3 \\
\hline$\beta_{1}$ & $-0.6768^{* * *}$ & $\begin{array}{c}-0.6940^{* * *} \\
(0.0426)\end{array}$ & $\begin{array}{c}-0.7632^{* * *} \\
(0.0496)\end{array}$ \\
(S.E.) & $(0.0410)$ & 0.2469 & $0.2755^{* * *}$ \\
$\left(\beta_{2}\right.$ &.$\cdot$ & $(0.1588)$ & $0.0976)$ \\
(S.E.) & &.$\cdot$ & $0.3161^{* *}$ \\
\hline$\beta_{3}$ &.. & 1105 & 1104 \\
(S.E.) & & $0.1608)$ \\
\hline D.F. & 1106 & $0.620437 \mathrm{E}+03$ & $0.616488 \mathrm{E}+03$ \\
\hline -Log Likelihood & $0.621627 \mathrm{E}+03$ &
\end{tabular}

Variables with $* * *$, and $* * *$ are significant at the 10,5 , and $1 \%$ level, respectively.

Conditional Bequests. Laitner and Sonnega [2010] find that financial respondents who report any inheritance from their in-laws tend to be more likely to report inheritances from their own relatives as well. Laitner and Sonnega suggest that this might be evidence of intentional bequest behavior: with assortative mating, intentional bequests are likely to occur in pairs, if at all, whereas pairs seem quite unlikely for the simplest accidental bequest model. A back of the envelope calculation (Laitner and Sonnega [2010, sect.6]) suggests that one could explain the conditional frequencies in the data if approximately one-third of inheritances are intentional - and mating is strongly assortative. This section examines conditional inheritances. 
Call Laitner and Sonnega's [2010] conjecture hypothesis $H_{1}$. Several types of evidence in the present paper cast doubt on $H_{1}$, as follows. (i) $H_{1}$ requires virtually perfectly assortative mating, at least among heirs to altruistic bequests. Section 2 above does find evidence of assortative mating: the estimated correlation coefficient for spousal economic backgrounds is $\widehat{\rho} \approx 0.2$, which is highly significantly different from 0 . However, it is also highly significantly different from 1.0 - or even from 0.5 . Hence, the degree of assortativity needed for $H_{1}$ seems in doubt. (See also Tables 1-3 above.) (ii) $H_{1}$ requires that a minority, say, $5-7 \%$ of the sample, receive altruistic transfers. Evidence of the implied monotonicity of $\beta_{2}, \ldots, \beta_{5}$ seems weak in Tables 5-6. What is more, under $H_{1}$ we would not be surprised to find a coefficient pattern resembling (13). Yet, Tables 5-6 provide no support for (13). (iii) Let

$$
\chi_{i}^{S P} \equiv \begin{cases}1, & \text { if financial respondent reports inheritance(s) to his/her spouse } \\ 0, & \text { otherwise. }\end{cases}
$$

Table 7, column 2, shows details of our sample for $\chi_{i}^{S P}=1$. Under $H_{1}$, we would expect a disproportionate number of $\chi_{i}^{S P}=1$ observations in rows 4-5. In fact, the opposite is true in Table 7.

Table 7. Observations, and Observations Conditional on Spousal-Inheritance Receipt for Financial Respondents, by Parent-to-Child Lifetime Resource Ratio

\begin{tabular}{|c|c|c|}
\hline $\begin{array}{c}\text { Parent-to-Child } \\
\text { Relative Resources }\end{array}$ & $\begin{array}{c}\text { Sample } \\
\text { Size }\end{array}$ & $\begin{array}{c}\text { Sample Conditional on } \\
\text { Financial Respondent } \\
\text { Spousal Inheritance }\end{array}$ \\
\hline Very Low & 600 & 35 \\
\hline Low & 196 & 25 \\
\hline Same & 228 & 22 \\
\hline High & 38 & 0 \\
\hline Very High & 45 & 84 \\
\hline Total & 1107 & \\
\hline
\end{tabular}

Consider a modified version of $H_{1}$, which we call $H_{2}$. The elements of $H_{2}$ are: (a) children of the poorest parents tend to receive bequests less frequently than others; (b) children of the poorest parents tend to mate with each other; and, (c) mating within row 1 of Table 7 - and within rows $2-5$ - is random.

$\mathrm{H}_{2}$ could be consistent with "sophisticated" assortative mating, as described above. We have noted that Tables 5-6 do provide support for property (a). Property (b) is a weaker version of assortativity than $H_{1}$ requires - hence it may be more consistent with Section 2. 
The underlying puzzle that we want to explain is the high conditional probability of financial-respondent inheritances. We have

$$
\operatorname{Prob}\left(\chi_{i}=1 \mid \chi_{i}^{S P}=1\right)=\frac{\operatorname{Prob}\left(\chi_{i}=1, \chi_{i}^{S P}=1\right)}{\operatorname{Prob}\left(\chi_{i}^{S P}=1\right)}
$$

Laitner and Sonnega [2010] find few reports by financial respondents of inheritances for their spouses. Assume that this is due to poor reporting and that in the actual population we have ${ }^{6}$

$$
\operatorname{Prob}\left(\chi_{i}^{S P}=1\right)=\operatorname{Prob}\left(\chi_{i}=1\right) .
$$

The conditional probability of interest is $\operatorname{Prob}\left(\chi_{i}=1 \mid \chi_{i}^{S P}=1\right)$. Laitner and Sonnega [2010] estimate its value to be in the range $0.40-0.45$, whereas their estimate of the unconditional probability, $\operatorname{Prob}\left(\chi_{i}=1\right)$, is only $0.20-0.25$.

Our regressions of Tables 5-6 imply a higher probability of inheriting for financial respondents in rows $2-5$, Table 7 , than row 1 . Noticing that Table 7 , column 1 , shows that row 1 comprises slightly over one-half of our sample, assume, for illustration, that

$$
\operatorname{Prob}\left(\chi_{i}^{2-5}=1\right) \approx 0.30 \text { and } P\left(\chi_{i}^{1}=1\right) \approx 0.10
$$

where $\chi_{i}^{1}$ and $\chi_{i}^{2-5}$ refer, respectively, to financial respondents in row 1 and rows 2-5 of Table 7 (and similarly for $\chi_{i}^{S P, 1}$ and $\chi_{i}^{S P, 2-5}$ below).

$H_{2}$, part b, assumes strongly assortative mating for row 1 and rows 2-5. Then

$$
\begin{aligned}
& \operatorname{Prob}\left(\chi_{i}=1, \chi_{i}^{S P}=1\right)=\operatorname{Prob}\left(\chi_{i}^{1}=1 \mid \chi_{i}^{S P, 1}=1\right) \cdot \operatorname{Prob}\left(\chi_{i}^{S P, 1}=1\right)+ \\
& \quad \operatorname{Prob}\left(\chi_{i}^{2-5}=1 \mid \chi_{i}^{S P, 2-5}=1\right) \cdot \operatorname{Prob}\left(\chi_{i}^{S P, 2-5}=1\right) .
\end{aligned}
$$

Assume (26). Given $H_{2},(23)$ and (26) imply

$$
\begin{aligned}
& \operatorname{Prob}\left(\chi_{i}=1 \mid \chi_{i}^{S P}=1\right) \\
& =\frac{1}{\operatorname{Prob}\left(\chi_{i}^{S P}=1\right)} \cdot\left\{\operatorname{Prob}\left(\chi_{i}^{1}=1 \mid \chi_{i}^{S P, 1}=1\right) \cdot \operatorname{Prob}\left(\chi_{i}^{S P, 1}=1\right)\right. \\
& \left.\quad+\operatorname{Prob}\left(\chi_{i}^{2-5}=1 \mid \chi_{i}^{S P, 2-5}=1\right) \cdot \operatorname{Prob}\left(\chi_{i}^{S P, 2-5}=1\right)\right\} \\
& =\frac{\operatorname{Prob}\left(\chi_{i}^{1}=1\right) \cdot \operatorname{Prob}\left(\chi_{i}^{S P}=1\right)+\operatorname{Prob}\left(\chi_{i}^{2-5}=1\right) \cdot \operatorname{Prob}\left(\chi_{i}^{S P, 2-5}=1\right)}{\operatorname{Prob}\left(\chi_{i}^{S P}=1\right)},
\end{aligned}
$$

where the last equality follows from $\mathrm{H}_{2}$, part c.

Finally, substituting from $(24)-(25)$ and $P\left(\chi_{i}=1\right)=0.20,(27)$ yields

\footnotetext{
6 See the literature on equal treatment of all children referenced in Laitner and Sonnega [2010].
} 


$$
\operatorname{Prob}\left(\chi_{i}=1 \mid \chi_{i}^{S P}=1\right)=\frac{0.3 \cdot 0.3+0.1 \cdot 0.1}{0.2}=\frac{0.10}{0.20}=0.50 .
$$

Thus, $H_{2}$ seems to be able to explain the high conditional probability in the data rather straightforwardly. On the basis of Tables 1-7, we favor it, at this point, over $H_{1}$.

5 Conclusion. We have studied data on the private intergenerational transfers of respondents in the original HRS cohort. As Laitner and Sonnega [2010] show, these data are unusually comprehensive.

We set up a simple model that includes both altruistic and accidental bequests. We argue that looking for one type of bequest behavior in isolation may be futile, as the two could easily be intermixed in practice.

We find some evidence of altruistic bequest behavior, but the support seems limited. The HRS enables us to trace the origin of individual inheritances, and earlier work suggested that there are anomalously many paired inheritances for both spouses within couples. The present paper suggests that a model of accidental bequests somewhat more sophisticated than the simplest case may be able to account for the pairing.

In general, we find several additional types of support for the modified accidental model of bequests. First, correlations of economic background between spouses seem positive but hardly exact. Our framework with accidental bequests is less demanding in this respect, and, thus, it may provide a better fit with the evidence. Second, our regressions show differences in inheritances between respondents with the poorest parents and everyone else - but not differences between respondents with very prosperous, as opposed to moderately prosperous, parents. An altruistic theory of bequest behavior would seem to imply that the second type of difference should be apparent. The modified accidental model would not — but it does suggest an explanation for differences of the first variety. 


\section{References}

[1] Altonji, J.G., Hayashi, F., Kotlikoff, L.J., "Is the Extended Family Altruistically Linked? Direct Tests Using Micro Data." American Economic Review 82, no. 5 (1992): 1177-1198.

[2] Altonji, J.G., Hayashi, F., Kotlikoff, L.J., "Parental Altruism and Inter Vivos Transfers: Theory and Evidence." Journal of Political Economy 105, no. 6 (1997): 11211166.

[3] Auerbach, Alan J., and Kotlikoff, Laurence J. Dynamic Fiscal Policy. Cambridge: Cambridge University Press, 1987.

[4] Barro, R.J., "Are Government Bonds Net Worth?" Journal of Political Economy 82 (1974): 1095-1117.

[5] Becker, G.S., "A Theory of Social Interactions." Journal of Political Economy 82, no. 6 (1974): 1063-1093.

[6] Becker, G.S. Human Capital, Second Edition. Chicago: University of Chicago Press, 1980.

[7] Becker, G.S., and Tomes, N., "An Equilibrium Theory of the Distribution of Income and Intergenerational Mobility." Journal of Political Economy 87, no. 6 (1979): 11531189.

[8] Blinder, A.B., Toward an Economic Theory of Income Distribution. Cambridge, MA: MIT Press, 1974.

[9] Davies, James B., "Uncertain Lifetime, Consumption, and Dissaving in Retirement." Journal of Political Economy 89 (June 1981): 561-577.

[10] DeNardi, Mariacristina; French, Eric; and, John Bailey Jones, "Why Do the Elderly Save? The Role of Medical Expenses." Journal of Political Economy 118, No. 1 (February 2010): 39-75.

[11] Friedman, B., and Warshawsky, M., "The Cost of Annuities: Implications for Saving Behavior and Bequests." Quarterly Journal of Economics 105, no. 1 (1990): 135-154.

[12] Hurd, Michael, "Savings of the Elderly and Desired Bequests." American Economic Review 77, no. 3 (1987): 298-312.

[13] Hurd, M.D., "Mortality Risk and Bequests." Econometrica 57, no. 4 (1989): 779-814.

[14] Kotlikoff, L.J., and Spivak, A., "The Family as an Incomplete Annuities Market," Journal of Political Economy 89 (1981): 372-391.

[15] Kotlikoff, L.J., "Intergenerational Transfers and Savings," Journal of Economic Perspectives 2 (1988): 41-58.

[16] Laitner John, "Modeling Marital Connections along Family Lines." Journal of Political Economy 99, no. 6 (1991): 1123-1141.

[17] Laitner, John, "Random Earnings Differences, Lifetime Liquidity Constraints, and Altruistic Intergenerational Transfers." Journal of Economic Theory 58, no. 2 (December 1992): 135-170. 
[18] Laitner, John, "Secular Changes in Wealth Inequality and Inheritance." The Economic Journal 111, no. 474 (October 2001): 349-371.

[19] Laitner, John, "Wealth Inequality and Altruistic Bequests." American Economic Review 92, no. 2 (May 2002): 270-273.

[20] Laitner, J., and Juster, F. T., "New Evidence on Altruism: A Study of TIAA-CREF Retirees." American Economic Review 86, no. 4 (September 1996): 893-908.

[21] Laitner, J., and Ohlsson, H., "Bequest Motives: A Comparison of Sweden and the United States." Journal of Public Economics 79, no. 1 (January 2001): 205-236.

[22] Laitner, J., and Sonnega, A., "Intergenerational Transfers in the Health and Retirement Study Data." MRRC working paper WP2010-239 (2010).

[23] Laitner, John, and Dmitriy Stolyarov, "Health Status and Post-Retirement Wealth Decumulation," mimeo University of Michigan, 2012.

[24] Modigliani, Franco, "Life Cycle, Individual Thrift, and the Wealth of Nations." American Economic Review 76, no. 3 (June 1986): 297-313.

[25] Modigliani, Franco, "The Role of Intergenerational Transfers and Life Cycle Saving in the Accumulation of Wealth." Journal of Economic Perspectives 2, no. 2 (Spring 1988): 15-40.

[26] Sinclair, Sven H., and Kent A. Smetters, "Health Shocks and the Demand for Annuities," Technical Paper Series Congressional Budget Office, Washington, DC, July 2004. 